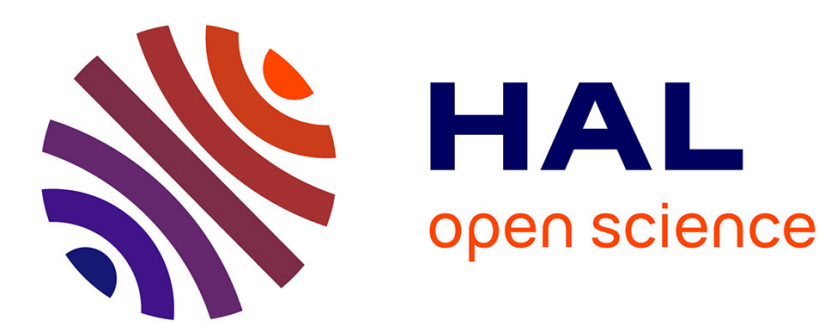

\title{
Regulatory failure of copyright law through the lenses of autopoietic systems theory
}

Katarzyna Gracz, Primavera de Filippi

\section{To cite this version:}

Katarzyna Gracz, Primavera de Filippi. Regulatory failure of copyright law through the lenses of autopoietic systems theory. International Journal of Law and Information Technology, 2014, pp.46. hal-01026113

\section{HAL Id: hal-01026113 \\ https://hal.science/hal-01026113}

Submitted on 19 Jul 2014

HAL is a multi-disciplinary open access archive for the deposit and dissemination of scientific research documents, whether they are published or not. The documents may come from teaching and research institutions in France or abroad, or from public or private research centers.
L'archive ouverte pluridisciplinaire HAL, est destinée au dépôt et à la diffusion de documents scientifiques de niveau recherche, publiés ou non, émanant des établissements d'enseignement et de recherche français ou étrangers, des laboratoires publics ou privés. 


\title{
Regulatory failure of copyright law through the lenses of autopoietic systems theory
}

\author{
Katarzyna Gracz, European University Institute ${ }^{1}$ \\ Primavera De Filippi, Berkman Center for Internet \& Society at Harvard Law School
}

\begin{abstract}
:
The paper explores the mechanisms that led to the current crisis of copyright law in the digital environment (understood as its inability to regulate social dynamics as regards the production, dissemination and access to creative works) by applying the concept of law as an autopoietic system. It analyses how the copyright regime (a subsystem of the legal system) evolved over time, by scrutinizing the interdependencies between copyright law and the other constitutive systems of its environment: the creative system (concerned with the creation, reproduction, distribution, and access to creative works) the political system (comprising both the State and the Church), the economic system (ruled by right holders and intermediaries on the market for creative works), and the technological system.

It will be shown that every new development in the technological system irritated the remaining systems, thereby stimulating the evolution of the overall ecosystem. For a long time, copyright law managed to properly adjust to the environmental changes brought by technological developments, so as to successfully regulate the production, dissemination and access to creative works. It is only with the advent of Internet and digital technologies that copyright law's selective response to environmental stimuli resulted in its failure to adapt to the new reality and, consequently, in the loss of its regulative power. Reacting mostly to the pressures of the economic and political systems (i.e. the lobbying of right holders and intermediaries), while neglecting the needs of the creative system, and even failing to adjust to the specificities of the changing technological system, copyright law eventually disrupted the balance of the surrounding environment. Furthering the economic interests of intermediaries (often at the expense of the public and in certain cases of the authors) created a series of divergences between legal norms increasingly restricting the access, use and reuse of creative works - and social norms-(produced within the creative system, and-supported by the new opportunities of digital technologies), which advocate for the free use and reuse of digital works. Over the years, copyright law distanciated itself so much from the social reality in which it operates that it has lost most of its credibility and applicability in the digital world.

Hence, the paper contends that, for copyright law to successfully regulate the production, dissemination and access to cultural works, it must be radically reformed in light of the intrinsic logic and needs of all constitutive systems of modern society, without favoring those of the economic and political systems over those of the creative system. It concludes that society (as a whole) might only benefit from the new opportunities offered by digital technologies if copyright law properly adapts to the digital era by embracing - rather than opposing - the specificities of the digital world.
\end{abstract}

\footnotetext{
${ }^{1}$ The article has been developed jointly by the two authors, although the underlying ideas stem from Katarzyna Gracz's PhD thesis „Copyright in decline? Systems theory, autopoiesis of law and the crisis of ${ }^{1}$ copyright in the digital era”, which is being currently finalised under the supervision of Prof. Giovanni Sartor at the European University Institute.
} 


\section{Introduction}

Over recent years, technological progress enabled the development of new mechanisms for the production, dissemination and access to information. New media emerged, marking the shift from primitive means of communication (such as the telegraph or the telephone) and traditional mass media (such as radio or television) allowing exclusively for one-to-one or one-to-many systems of communication (broadcasting) towards modern information and communication technologies (ICTs) whose architecture is such as to facilitate the deployment of new systems based on a many-to-one or many-to-many approach to communication. ${ }^{2}$ In this regard, the Internet - as a global network allowing for both synchronous and asynchronous communication - gradually established itself as the standard for new media, with all the implications it entails on the way we work and communicate online.

The advent of the Internet and digital technologies had a considerable impact on most of our social interactions and cultural practices. In particular, the growing popularity of the World Wide Web and, more recently, the Web 2.0 induced a drastic change in many activities related to information production and consumption. While these activities were, for a long time, undertaken by distinct categories of actors (producers on the one hand, and consumers on the other), their boundaries are, nowadays, increasingly blurring into each other with the emergence of the hybrid figure of the "prosumer" and consumes information. Moreover, as the medium turns digital, it becomes much easier to reproduce, disseminate, share or exchange information with one another, as well as to remix or mash it up with other types of information or works. ${ }^{4}$

New media, new actors, along with new production and consumption practices require the establishment of new laws - or, at least, the reform of preexisting laws. Ever since its conception, copyright law has thus been constantly evolving to keep up with technological advances, while trying to preserve the balance between the various social systems involved in the production, dissemination and access to creative works.

This paper will analyse four fundamental phases that are perceived as landmarks in the development of copyright law and its attempts to adapt to the novel environment: ${ }^{5}$ Section III will focus on the shift from the manuscript era to the age of print; from the granting of royal privileges over the publication of literary works to the advent of copyright law establishing a limited monopoly over the exploitation of any original work of authorship. Section IV will analyse the advent of the industrial society and the widespread deployment of technological tools allowing for the massive reproduction of works. Section V will then investigate the impact that Internet and digital technologies had on the social norms produced within the creative system and the economic interests of right holders and intermediaries within the cultural industry (here perceived as belonging to the economic system). ${ }^{6}$

2 For more details, see Morris, M., \& Ogan, C. 'The Internet as mass medium.' (1996) Journal of Computer $\square$ Mediated Communication, 1(4), 0-0.

3 Already in 1972, Marshall McLuhan and Barrington Nevitt suggested that, with the advent of digital technologies, the consumer would progressively become a producer. McLuhan, M., \& Nevitt, B. (1972). Take today: The executive as dropout (p. 11). New York: Harcourt Brace Jovanovich. The term "prosumer" was, however, only coined in 1980 by futurologist Alvin Toffler who predicted that, eventually, the role of producers and consumers would begin to blur and merge. A. Toffler, The third wave: The classic study of tomorrow. (New York, NY: Bantam 1980).

4 O'Brien, D. S., \& Fitzgerald, B. F. 'Mashups, remixes and copyright law'. (2006) Internet Law Bulletin, 9(2), 17-19.

${ }^{5}$ For the purpose of this paper, we do not attempt to reconstruct the entire history of the copyright law, rather, we merely focus on the major landmarks that have dictated its development.

6 See: Katarzyna Gracz, 'Bridging the Gaps Between Social and Legal Norms Concerning Protection of Intellectual and Artistic Creations: On the Crisis of Copyright Law in the Digital Era.' (2013) The Journal of World Intellectual Property, (2013) Vol. xxx, no. 
Drawing from systems theory as a theoretical framework (illustrated in Section II), the concept of law as an autopoietic system operating within a broader ecosystem will be applied throughout the paper, in order to assess whether, and how, copyright law effectively adapted itself to the changing environment. Every technological breakthrough contributed to irritating the other components of the ecosystem, eventually leading them into their consequent stages of evolution. Yet, it will be argued that, although the traditional rationale of copyright law was to protect the interests of authors, while ensuring that society as a whole would ultimately benefit from access to a thriving cultural heritage - what in fact constitutes a balance between the economic and the creative systems - the recent evolution of copyright law that took place in response to subsequent environmental changes eventually disrupted that balance. Indeed, copyright law's attempt to preserve the traditional status quo that established itself in the physical world - by trying, in vain, to transpose it into the digital world - reveals a fundamental bias towards furthering the economic interests of right holders (as distinct from the original authors) to the detriment of end-users and, sometimes, even of authors themselves.

xxx, pp. 1-19, where the same historical patterns have been analysed. 


\section{Theoretical Stance}

The theoretical framework of this analysis essentially relies on modern social systems theory. It draws heavily on the concept of law as an autopoietic system, mainly developed in the works of Niklas Luhmann $^{7}$ and Gunther Teubner ${ }^{8}$, although our considerations sometimes differ considerably from those of the 'founding fathers', and especially from Luhmann's standpoint. All such cases will be duly underlined throughout the paper.

\section{Introduction to Systems theory}

Systems theory is based on an evolutionary paradigm that perceives society as a system of dynamic communications. It relies on the idea of-'societal differentiation' ${ }^{99}$ according to which modern society-is not a homogeneous system, but is rather a combination of differentiated systems and subsystems (such as the legal, economic, political, or scientific systems) which serve different functions.

Function refers to the main contribution that the given system makes to the overall operation of society (for instance, the function of the legal system is to maintain normative expectations, the function of science is to accumulate knowledge etc.). What unequivocally differentiates every system from another is its distinctive code-of communication (e.g. legal/illegal for the legal system, true/untrue for the scientific system), which also constitutes the basis for its identity as an autonomous system. By matching communications to its inner code, each system ultimately selects only those communications which are specific to itself. This allows it to maintain its autonomy as a system that remains distinct from others and is able to establish its own boundaries (e.g. when deciding whether or not a given communicate belongs to its logic, the legal system applies the binary code of legal versus illegal: all the communicates that may be subsumed to this code are part of the legal system, whereas everything else belongs to the external environment).

According to systems theory, some subsystems of society (the general social system) have acquired so much independence from the rest of the ecosystem that they can be regarded as autonomous units of communication which are capable of reproducing and maintaining themselves - in other words, they have become autopoietic.

Autopoietic systems construct and reconstruct themselves in a process of constant self-reference, ${ }^{10}$

${ }^{7}$ Especially: Niklas Luhmann, Law as a Social System (Oxford University Press, Oxford, 2004).

8 Especially: Gunther Teubner, Law as an Autopoietic System (Blackwell Publishers, Oxford, 1993).

${ }^{9}$ See Erkki Sevänen, Art as an Autopoietic Subsystem of Modern Society: A Critical Analysis of the Concepts of Art and Autopoietic Systems in Luhmann's Late Production, Theory Culture Society, 2001 18:75, p. 79.

10 "The idea of self-reference and autopoiesis presupposes that systems seek the fixed points of their mode of operation in themselves and not in the environmental conditions to which they adapt themselves as best they can (as is assumed in open systems). To put it more precisely, they look for these points in a self-description which functions as a programme of internal 
autonomously redefining their own boundaries through the observation of themselves and the changes incurring in their surrounding environment ${ }^{11}$. Although indirectly affected by its ecosystem, an autopoietic system is not directly influenced by it: it is not for the environment to decide what belongs to the system, but for the system itself to decide what to take into its own boundaries. But autopoiesis is ultimately a matter of degree: some systems can be more or less independent from their surrounding environment (and therefore more or less autopoietic) than others. ${ }^{12}$

While they are not directly affected by the changes in their environment, autopoietic systems can, nonetheless, establish a series of indirect and reciprocal interactions between one another. ${ }^{13}$ They are

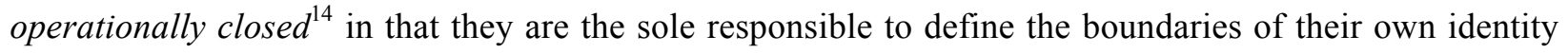
(rather than the environment or an external observer), but cognitively open in that they remain 'connected with their social environments through mechanisms of interference which operate between systems. ${ }^{15}$. According to the concept of 'operational closure' (i.e. the property of being operationally closed), a system has no direct access to its environment, but only to its own inner representation of that environment, as seen through the specific code of the system. Different systems may irritate each other when the operations of one system trigger responses in the other and vice versa. This is known in systems theory as the phenomenon of 'structural coupling, ${ }^{16}$ where 'the 'coupling' of [any given] system with its actual environment and the reciprocal restraints that arise from this are the result of the overlapping of events, structures, and processes within and outside [of the system]. ${ }^{17}$ Yet, for this phenomenon to occur, a system A must recognise the operation of another system B as meaningful. While system A is not directly affected by the operations of system B (because of the operational closure of the system), it is indirectly influenced by them as a result of the internal constructions of these operations produced from within the system. To give an example, the concept of property is understood differently by the legal system (which regulates the ownership of things) and the economic system (which determines the value of things). The legal system may respond to the environmental stimuli stemming from the economic system, not as a result of economic operations as such, but rather as a consequence of the legal interpretation of these operations. Notwithstanding the difference between their respective codes of communication, these two systems are, to some extent, interdependent: they each need the other to perform a function that could not be achieved within their own closure alone (e.g. while the legal system

regulation, organizing the system in such a way that it corresponds to this self-description." Gunther Teubner (1993) op.cit.p.15.

11 N.Luhmann (2004), op.cit.

12 The graduality of autopoiesis is claimed here against Luhmann who asserted that a system is either autopoietic or it is not: 'There are no half autopoietic, half allopoietic systems.' See: Niklas Luhmann, Autopoiesis als soziologischer Begriff. In Differenzierung: Beiträge zu Luhmanns Theorie sozialer Systeme, (Suhrkamp, Frankfurt, 1987), p.318. This alternative view of autopoiesis characterised by more flexibility was claimed however by other theorists. See e.g.: Gunther Teubner (1993) op.cit.p. 31; Gerhard Roth, Autopoiese und Kognition: Die Theorie H.R. Maturanas und die Notwendigkeit ihrer Weiterentwicklung. In S.J.Smidt (ed.), Der Diskurs des Radikalen Konstruktivismus (Suhrkamp, Frankfurt, 1987), p.400.

13 Gunther Teubner (1993) op.cit. p.21.

14 See e.g. Niklas Luhmann (2004) op.cit. pp. 76-142; Gunther Teubner (1993) op.cit. p. 65; Roger Cotterrel, 'The Representation of Law's Autonomy in autopoiesis Theory' in Jiři Přibán and David Nelken (eds), Law's New Boundaries: The Consequences Of Legal autopoiesis (Ashgate, 2001) p. 99.

15 Gunther Teubner (1993) op.cit. p.65.

16 "A central element within the theory of autopoiesis is the concept of structural coupling which refers to the relation between systems and their environments. As explained above environmental events can trigger internal processes in an autopoietic system but the concrete processes triggered (and whether any processes are triggered at all) are determined by the structures of the system." See: Richard Nobles and David Schiff Introduction to Niklas Luhmann Law as a Social System (Oxford University Press, New York, 2004), p.42-43.

17 Gunther Teubner (1993) op.cit. p.65. 
cannot establish the values of things, the economic system can only determine the values of things after the principle of ownership has been established by the legal system). ${ }^{18}$

Conversely, 'cognitive openness' (i.e. the property of being cognitively open) allows for a system to evolve over time so as to promptly react to the changes in the ecosystem. Thus, an autopoietic system can learn to adjust its internal code of communications in response to the surrounding stimuli of its environment, by 'making communications that alter possibilities of what will, in future, constitute a communication within that system'. ${ }^{19}$ Yet, the universal capability to respond to environmental changes does not entail that all systems do actually respond: the adaptability of each system to the modifying environment ultimately depends on its internal potential. ${ }^{20}$

\section{Law as a normative autopoietic system}

According to systems theory, law is a normative system ${ }^{21}$ that is distinct from other systems, but that nonetheless interacts with other normative systems (such as religion and morality). It is operationally closed in that it is setting the boundaries of its own identity through a process of recursive self-reference. Legal practice is based on connecting new legal operations to the existing ones in accordance with the general logic of the system. The communications that are recognised by the legal system as belonging to its logic - i.e. as legal - are valid, those that are not recognised as such are invalid. ${ }^{22}$

As a social autopoietic system, law distinguishes itself from other self-referential systems through the combination of the function it assumes in society and the specific code of communication it employs. ${ }^{23}$ The function of law is to produce and maintain normative expectations, even though they may not always be met (i.e. "what is" does not equal "what ought to be"). The specific code of the legal system relies on a binary distinction: legal/illegal. At the core of the legal system's operations lies the process of filtering the surrounding reality in order to divide all environmental stimuli into two categories: legal norms or facts. Legal norms are all the communications that the law recognises as its own. All the rest are facts. Even the norms of other systems - such as moral, religious, or social norms - are classified by the legal system as facts, unless they correspond to actual legal norms. ${ }^{24}$

\footnotetext{
18 Ibidem, p.44.

19 See: R. Nobles and D. Schiff D. Introduction to Luhmann (2004) op.cit. p.8.

20 Teubner Gunther and Willke Helmut, 'Can Social Systems be Viewed as Autopoietic', LSE Complexity Study Group, Meeting No. 3, 18 June 1993, London: London School of Economics, (1993) http://www.Ise.ac.uk/researchAndExpertise/units/complexity/events/1995-1999/1997/studygroup_18june97.aspx> accessed 9 April 2014

21 N. Luhmann (2004), op.cit.

22 See: R. Nobles and D. Schiff D. Introduction to Luhmann (2004) op.cit. 12-13.

23

${ }^{23}$ There are other normative systems (e.g. morality, religion, social norms) that assume the same function, i.e. they maintain normative expectations; however only law does it through the legal / illegal code. See N. Luhmann (2004), op.cit. p.138, 239, 240, 429.

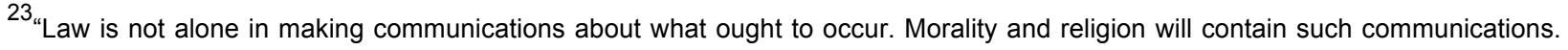
Thus function alone is not sufficient to differentiate law. But what is sufficient is that law achieves its function by coding events in its environment by using a binary code that is unique to itself: legal/illegal."R. Nobles and D. Schiff D. Introduction to Luhmann (2004) op.cit. p.9.

${ }^{24}$ For example, the moral and religious norm "Thou shall not kill" mirrors the legal norm incorporated in the criminal code. In such cases the legal system is not indifferent to a rule, although what it actually reacts to is its own "legal" encoding of the norm. Certain moral and religious norms entered the legal system in the process of "translation" into the "legal code" and became legal norms the "slavers" of the legal system. Nonetheless, the operations of other systems, even if normative in nature from the perspective of other systems - do not become legal operations automatically - they have to be recognised by law itself as belonging to its own logic and being meaningful from the legal perspective. On passing the verification, eligible norms are encoded in the legal system in the binary code specific to law: legal/illegal. See: Jürgen Habermas, Faktizität und Geltung: Beiträge zur Diskurstheorie des Rechts und des Demokratischen Rechtstaats (Suhrkamp Verlag KG, 1992), 250; For the English translation see: Jürgen Habermas,
} 
Legal system, like other autopoietic systems, may evolve in response to the changes in its environment through the 'processes of co-evolution in which the co-evolving systems exert an indirect influence on each other'. ${ }^{25}$ Law's evolution is conditioned by its operational closure on one hand, and its cognitive openness on the other. As a result of operational closure, the legal system retains its own distinctiveness and independence from other systems. Law reconstructs the external world through its internal operations, producing an autonomous reality that guides and determines its operations. At the same time, cognitive openness allows law to be connected with the surrounding environment through mechanisms of interference that operate between systems. $^{26}$ The legal system creates a network of mutual interdependencies together with the systems that it is in the closest relationship with. For the purpose of this paper, we will focus on the interplay between the legal system and the systems of creativity, politics, economics and technology because many of their communications are meaningful within the realm of copyright law.

This combination of operative closure and cognitive openness allows for the legal system 'to regulate society by regulating itself. ${ }^{27}$ Yet, given that different systems necessarily rely on different codes of communications, the inner logic of the legal system cannot be directly imposed on its surrounding systems. Its communicates can only be indirectly assimilated by other systems after having been acknowledged and re-interpreted according to the plurality of their logics.

As previously mentioned, the function of the legal system is to produce and maintain normative expectations as regards what is legal or illegal. Yet, these normative expectations can be completely detached from social reality insofar as they do not account for the manner in which they are understood through the lenses of every constitutive system of society. Thus, the legal system must not try to enforce its own understanding of social reality in order to balance individual and/or collective interests according to its own logic; rather, it should try and provide an equilibrium between the different systems that coexist within the environment, according to a plurality of logics. ${ }^{28}$ For law to be able to regulate society, it has to perceive it as a combination of independent and autonomous systems which evolve on their own terms, and only to the extent that they consider it necessary. Hence, social regulation through law cannot be achieved directly, only indirect regulation is possible to the extent that the legal system can provide the proper stimuli to persuade other systems to evolve, so as to adjust to the modified environment in order to re-establish an equilibrium within the whole ecosystem. ${ }^{29}$

This paper contends that such equilibrium was lost with the advent of digital technologies, due to the fact that legal system has been trying to adapt to the new environment by reacting mostly in response to the

Between Facts and Norms: Contribution to a Discourse Theory of Law and Democracy (William Rehg trans., 1996); Gunther Teubner, 'De Collisione Discursuum: Communicative Rationalities in Law, Morality and Politics', 17 Cardozo Law Review (1996), 901-918, p.911, where the author compares the transfer of a norm from one normative system to another through the process of "enslavement".

25 Gunther Teubner (1993) op.cit. p.61.

${ }^{26}$ Ibidem, p.65.

27 Ibidem.

28 "The point here would be to bring out into the open the intrinsic logic, functional requirements, and guiding principles of the conflicting social fields and to balance them." Gunther Teubner (1993) op.cit. p.112.

${ }^{29}$ This is the idea that is found in the concept of 'reflexive law' as elaborated by Gunther Teubner in Ibidem, p. 64-99. See also: Gunther Teubner, Substantive and Reflexive elements in Modern Law, EUI Working Paper No.14, (European University Institute, San Domenico, 1982); John Paterson and Gunther Teubner Changing Maps: Empirical Legal Autopoiesis in Reza Banakar and Max Travers (eds.) Theory and Method in Socio-Legal Research, Oñati International Series in Law and Society (Hart Publishing, Oxford and Portland Oregon, 2005) pp.215-237 
stimuli stemming from some systems but not others. It is claimed, therefore, that copyright law should try and re-establish a balance between all those systems that directly or indirectly affect the production, dissemination and access to digital works.

\section{Description of the analysed model}

This paper draws from systems theory to analyse the ecosystem of copyright law and describe its historical development as an autopoietic system: how it has evolved so far, and what is the cause of its regulatory failure in the digital world. To do so, the study reconstructs the mutual interplay between the legal system and the other constitutive systems of the ecosystem: the system of creativity, politics, economics and technology. The model consists of different functional systems (rather than different stakeholders) because the same stakeholder might belong to one or more of these systems, e.g. authors might belong both to the cultural system as 'artists' and to the economic system as 'right holders'.

\section{Legal system}

As previously described in more details, the legal system relies on the binary code "legal/illegal" in order to establish and maintain normative expectations as to what is legal or illegal. Yet, the process of functional differentiation that is typical of modern society is also found in the modern legal system, which is characterised by a 'fragmentation of law into a multitude of special fields, ${ }^{30}$. Copyright law is an example of such a specialisation resulting from the functional differentiation of the general legal system. It is a subsystem of the legal system that focuses on a particular area of law: its function is to maintain normative expectations as regards what is legal or illegal when it comes to the production, dissemination and access to creative works.

\section{Creative system}

The creative system encompasses everything belonging to the realm of creativity, as regards the production, dissemination and access to creative works. We employ the term "creativity" - as opposed to "art" or "culture" --in order to provide a more accurate definition of the boundaries of the system. Indeed, the definition of "art" is too narrow", as it would exclude scientific publications and other non-artistic, but nonetheless creative material (such as software, models, and so on) from the scope of analysis. "Culture", on the other hand, is too broad, in that it refers to the whole set of shared values and beliefs that characterises a particular community or society. "Creativity" also distinguishes itself from the concept of "innovation" to the extent that it does not necessarily require something to be either novel or innovative $^{32}$ but merely to be "original", in the sense that it is the result of the creative or intellectual endeavour of the author.

In our model, therefore, the creative system is regarded as an autopoietic system that relies on the binary

\footnotetext{
${ }^{30}$ Gunther Teubner, ‘De Collisione Discursuum (1996) op.cit., p.916.

31 Compare with: Erkki Sevänen, op.cit.

32 As opposed to the system of creativity, which has been codified by the system of copyright law, the system of innovation has been codified by patent law.
} 
code "original/conventional" in order to determine its own boundaries ${ }^{33}$. Although we acknowledge the criticism that, of course, this code is used by many other sub-systems of modern society ${ }^{34}$, we contend, nonetheless, that the creative system distinguishes itself from these other sub-systems to the extent that this code represents its main code of communication - as opposed to other sub-systems which only use it as an ancillary code in their communications. ${ }^{35}$

The function of the creative system is to produce and provide access to creative works. While the creative work represents the medium of communication ${ }^{36}$, the "creative system" does not focus on the object of creativity per se, but rather on the act of creativity. It is understood as comprising every act of communication that involves a creative work. As such, the creative system is made of four elementary constituents - four interrelated components, which are closely linked together: ${ }^{37}$

1. "creation" refers to the production of a new work, or the making of a derivative work based on one or more previous works by an individual (understood here as the author).

2. "reproduction" refers to the actual copying or reproduction - in any form and by any means - of a work by a performer and/or a member of the general public;

3. "distribution" refers to the communication, dissemination or making available of a work by the general public (acting outside of the commercial realm);

4. "consumption" refers to the mere access and consumption of a work by the general public (understood here to assume a passive role);

Each of these components produces its own social norms ${ }^{38}$ - understood as normative statements ${ }^{39}$ that identify social expectations arising in the course of repeated interactions. ${ }^{40}$ These norms are enforced either through the application of internal sanctions, emerging from the internalisation of the social norms within the human $\operatorname{mind}^{41}$ and/or through the application of external, informal (i.e. non-legal) social

33 See: Niklas Luhmann Die Aufdifferenzierung des Kunstsystems (Berteli Verlag, Bern, 1994) pp. 95-99, where the author elaborates on possible codes for the system of art, which however he finally fails to describe because of the inherent problems with defining a unique code that would be used only and exclusively by art.

34 See: Erkki Sevänen, pp.94-95.

${ }^{35}$ A similar situation arises in case of the system of science, which differentiates itself from the surrounding environment through the code "true/untrue". Although this code is also used as an auxiliary code by many other social systems, only science uses it as its main, constituent code.

${ }^{36}$ Apart from having their specific communication codes, autopoietic social systems are also characterised by their media, e.g. the medium of the political system is power, that of the legal system is legality, whereas the medium of the economic system is money. See: Erkki Sevänen, pp.82-83.

37 "Whatever they consist from - elements, structures, processes, boundaries -, systems are conceived to produce all their elementary constituents by their own production processes." Rudolf Stichweh, Systems Theory in: Bertrand Badie et al. (eds.), International Encyclopedia of Political Science. Sage New York, 2011, Vol. 8. Systems Theory. Pp. 2579-2582. "The structures themselves however are not pre-given in any sense, as in structuralist theories, but are themselves the product of the autopoietic system. In other words, in its reproduction the system produces and reproduces its very own structures of reproduction." David Seidl, Luhmann's theory of autopoietic social systems, (Ludwig-Maximilians-Universität: München, 2004), p. 4, available at: http://www.zfog.bwl.uni-muenchen.de/files/mitarbeiter/paper2004 2.pdf; reference made to Niklas Luhmann, Organisation und Entscheidung. (Opladen: Westdeutscher Verlag, 2000)), p.47.

${ }^{38}$ For a general review of sociological theories dealing with the concept of 'social norms', see: e.g. Christine Horne 'Sociological Perspectives on the Emergence of Social Norms', in Michael Hechter and Karl-Dieter Opp, Social Norms, (Russell Sage Foundation, 2005), pp. 3-34.'

39 See: e.g. Homans George C., Social Behavior: Its Elementary Forms (New York: Harcourt, Brace 1961), p.12.

40 See: e.g. Dennis Wrong, The Problem Of Order: What Unites and Divides a Society (New York: Free Press, 1994), p.48; Christina Bicchieri, Learning To Cooperate, in Christina Bicchieri, Richard Jeffry and Brian Skyrms (eds), The Dynamics Of Norms, (New York: Cambridge University Press, 1997), pp. 25-27.

${ }^{41}$ For a discussion of internalization of the social norms see e.g. Emile Durkheim, The Elementary Forms Of The Religious Life (New York: Free Press, 1915), pp. 236-245; Emile Durkheim, Suicide (New York: Free Press, 1951). 
sanctions $^{42}$. Different actors will abide to different social norms: e.g. the norms pertaining to the category of "authors" (as regards plagiarism, remix, parody, and so on) might differ from the social norms pertaining to the "general public" (as regards private copying, citation, etc.). Some of these norms might, but do not necessarily have to, coincide with legal norms - and even when they do coincide, they do, however, ultimately belong to two different normative systems.

As an autopoietic system, the creative system decides by itself what belongs to the realm of 'creativity' and what does not, according to the binary code "original/conventional". Copyright law represents an attempt at "codifying" the creative system into law. Hence, the subject matter of copyright law is (indirectly) derived from the interpretation of the law as to what shall or shall not be regarded as a creative work. In this sense, copyright law stipulates that for a work to qualify as an original work of authorship (and therefore to be eligible for copyright protection), it must be original (in the sense that it originates from the author) and it must carry the stamp of the personality of the author. Understanding the relationship between the creative system and the provision of copyright law is important in our analysis, in order to assess, on the one hand, whether or not copyright law has indeed succeeded in codifying the logic of the creative system into its statutes, and, on the other hand, what are the causes of the similarities and/or dissimilarities that can be found between these two systems. In the remainder of the paper, our model will be used to show that, with the advent of Internet and digital technologies, important divergences have emerged between the logic of the creative system and the logic of copyright law. This is reflected by the growing discrepancies between legal norms and social norms, which can be regarded as one of the main causes for the regulatory failure of copyright.

\section{Political system}

The autopoietic system of politics - whose function is to make collectively binding decisions ${ }^{43}$ - relies on the binary code "governing/governed" to distinguish between superior power and subordinates. Governing authority relies in turn on a secondary code "government/opposition" 44 in order to assign alternatives to each side. The decision of what constitutes the government and what constitutes the opposition is not grounded in any inherent value, but rather depends on conditional programmes developed by specific structures within the political system (e.g. parliament, parties, forums, etc). ${ }^{45}$

The political system is relevant to our model because of its close interaction with the legal system. In particular, the incorporation of law within the government's conditional programmes through legislation had major implications on the development of the legal system: it contributed to the law becoming more responsive to its environment, by providing the legislative structure necessary for the legal system to structurally couple with other systems. ${ }^{46}$

In our model, we regard the political system as comprising both the State and the Church - two actors involved in the initial development and subsequent evolution of copyright law. While both were to some extent responsible for the introduction of privileges on the production and dissemination of cultural works

\footnotetext{
42 See e.g. Talcott Parsons, The Social System (New York: Free Press, 1952), p. 38; Emile Durkheim, The Determination of Moral Facts, in Sociology and Philosophy (London: Cohen and West, [1903] 1953), p. 36, 43.

43 See: R. Nobles and D. Schiff D. Introduction to Luhmann (2004) op.cit. p.39.

${ }^{44}$ Niklas Luhmann (2004), op.cit. p.378.

45 R. Nobles and D. Schiff D. Introduction to Luhmann (2004) op.cit. p.39.

46 Ibidem, p. 40.
} 
- the first step in the evolution of copyright law - other actors eventually entered the scene in order to influence the process of collective decision-making so as to achieve protection of their own interests within the legal system. In view of that, our model will also account for the interferences produced by the activities of lobby groups, coming from the economic system, on the one hand, and the cultural system, on the other hand.

\section{Economic system}

The autopoietic system of economy communicates through the "language of prices ${ }^{47}$ : it uses the binary

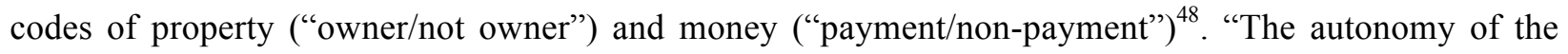
economy consists in the self-reproduction of acts of payment" $"$ in order to determine who owns what, and who is willing to pay for what.

Including the economic system into our model is useful because of its specific relationship to the legal system, with whom it is structurally coupled..$^{50}$ Contract law and property law - or, in our case, intellectual property law - are tools provided by the legal system in order to support or facilitate the operations of the economic system: while property law establishes the rules to distinguish between "owners" and "non-owners", contract law can be used by anyone willing to transfer property in exchange of compensation (or "payment"). ${ }^{51}$

Our model identifies two main components of the general economic system: right holders and intermediaries on the market for cultural works. The former category comprises both authors and third parties who hold the copyright in a work (including the intermediaries themselves). Both rely on the exclusivity of copyright law in order to maximize the profits deriving from the exploitation of content. The latter category consists of intermediaries that do not hold the copyright in the works. Their business

47 Gunther Teubner (1993) op.cit. p.102..

${ }^{48}$ Niklas Luhmann, 1992. 'Operational closure and structural coupling: the differentiation of the legal system.' Cardozo Law Review 13(5): 1419-1441.

49 Gunther Teubner (1993) op.cit. p. 75.

50 David Seidl,op.cit p. 4.

51 “....]institutions of contracts and rights (...) do not use system interference to motivate compliance in the legal environment. On the contrary, they avoid the problem of motivation. They can do this because they directly produce the interference between law and economy. Not two but three actions - namely, legal, social and economic - coincide in the institutions of contracts and rights. A contract is always economic communication, since it is an economic transaction; but it is also always a legal action, since it not only alters the legal position, but produces new legal norms. At the same time, as an exchange, it still remains part of the general social communication." Gunther Teubner (1993) op.cit. p. 92.

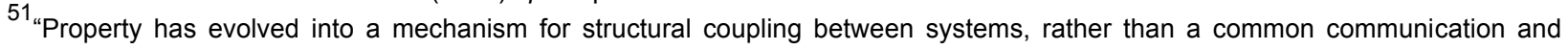
experience across society. Within law it can be distinguished from contract, or distinguished as a right in rem rather than a right in personam, or distinguished from obligations. The distinction drawn is always within the network of law's operations, depending on the legal question one is trying to answer, and the real and hypothetical cases one is trying to compare. (Such is the nature of legal argumentation.) These distinctions, which can be traced within legal histories (legal evolution) by reference to, among other things, changes to the causes of action (writs), are not the same distinctions by which property is understood and communicated about within the economic system. Economics has its own understanding of property. The economic system requires owners to be identified in order to know whose consents must be obtained in which circumstances, and to whom one must offer payment. This is a different network of communications using a common term within a different set of distinctions. The development of this understanding is part of the development of a market economy: a separate economic system." See: R. Nobles and D. Schiff D. Introduction to Luhmann (2004) op.cit. p.44.

51

51

51

51 
model is not based on the licensing of rights, but rather on the provision of copies (e.g. books, CDs, DVDs, MP3, etc) or services that exploit the works of third parties, either directly (e.g. iTunes, YouTube, etc.) or indirectly (e.g. infomediaries, device producers, etc.).

Distinguishing between these two components and analysing their corresponding patterns of behavior enable us to underline the fact that there are competing interests within the economy system itself (e.g. right holders versus intermediaries), as well as between the inner logic of the economic system and that of the other systems in the environment (e.g. economic system versus cultural system).

\section{Technological system}

Technology is approached in this paper in a broad sense, as the application of scientific knowledge for practical purposes. It has been defined by the American sociologist Read Bain to include "all tools, machines, utensils, weapons, instruments, housing, clothing, communicating and transporting devices and the skills by which we produce and use them." 52

We regard technology as an independent, autopoietic systems that relies on the binary code "functional/dysfunctional" in order to achieve its function, namely to provide society with the means "to do things' more efficiently. It differs from the other systems described in our model insofar as it is the only system that comprises both social components (e.g. knowledge, skills, etc.) and non-social ones (e.g. tools, devices, etc).

From an historical perspective - with regard to the production, dissemination and access to creative works - the technological system is also the only system that was not irritated by any of the other systems described within our own model. Mainly influenced by the system of science (which remains, however, outside of the scope of our analysis), the technological system can be regarded as the original trigger for the co-evolution of the rest of the ecosystem. The changes undertaken within its own boundaries significantly irritated its surrounding systems, leading to their subsequent adaptation to the new technological environment. In the remainder of the paper, we will focus, in particular, on three technological developments which have, in our view, led to an important paradigm shift in society: the advent of the printing press (section III.B), the deployment of cheap reproduction technologies (section IV), and, finally, the advent of Internet and digital technologies (section V).

$$
* * * * *
$$

The aim of this paper is to illustrate the dynamics between the different systems described so far, along with their respective logics. It will be contended that the regulatory failure of copyright law in the digital environment is a result of its unsuccessful attempt at establishing a balance within the ecosystem in which it operates. Copyright law tried to impose its own understanding as to what such a balance should look like by relying exclusively upon the inner logic of its own system. We will argue, however, that the perception of the copyright system is biased insofar as it does not equally acknowledge the stimuli of all its surrounding systems. Over the years, copyright law has given more and more weight to the stimuli coming from the political and economic system, increasingly ignoring the stimuli coming from the creative system (which is, in fact, the one that it was originally meant to regulate). By selectively

\footnotetext{
52 Bain Read, 'Technology and State Government', American Sociological Review, Vol. 2 (6) (1937), p. 860.
} 
acknowledging some stimuli and ignoring the others, the system of copyright law has progressively distanciated itself from the logic of the creative system. This spurred a conflict between two competing normative systems, both responsible for establishing and maintaining normative expectations as regards the creation, dissemination and access to creative works: the legal norms of the copyright regime, on the one hand, and the social norms produced within the creative system, on the other.

It is exactly this divergence between social and legal norms that is at the source of the regulatory failure of copyright law in the digital era. Yet, it will be shown that, even though the regulatory crisis of copyright law did not become apparent-until the introduction of Internet and digital technologies, it actually has its roots at the inception of the copyright regime - when the proprietary paradigm was first transposed from property law into the realm of copyright law.

From a systems theory perspective, the transposition of the proprietary paradigm into the realm of intellectual creations results from the lack of structural coupling between the legal system and all the relevant components of its environment. In response to the interferences resulting from the changing environment - technological advances, political pressures, emerging cultural practices and economic interests - the legal system did not structurally adapt to changes reflected by the surrounding systems (i.e. it did not structurally couple with them). Instead of applying a new solution that would modify its own structures, the legal system relied on the pre-existing structure of property (that was already within its own borders) and transposed it into the realm of intellectual property. This is, according to our view, what explains the recurrent bias of copyright law towards furthering the economic interests of right holders (as opposed to the creative interests of authors or the public). Indeed, the very concept of property rights is, ultimately, a result of the structural coupling between the legal system and the economic system. From the perspective of the ecosystem, the introduction of intellectual property underlines therefore the bias of copyright law towards the economic system, and its failure to adapt to the logics of the other systems.

While such bias subsisted ever since the conception of copyright law, it has become more apparent in the digital environment. Rather than acknowledging the new opportunities offered by digital technologies (i.e. by creating new structural couplings with both the technological and creative systems), copyright law attempted to replicate the rules of the physical world into the digital world, by stubbornly trying to apply old and inadequate patterns to an entirely new context. As a result, the law eventually had to increase the degree of exclusivity within the copyright regime (which has progressively become more restrictive in the digital world than in the physical world), thereby furthering the logic of economic system, while ignoring the emerging practices and social norms produced within the creative system. 


\section{At the outset}

\section{A. Manuscript culture}

The analysis starts at the era of manuscripts, an era with no copyright regulations and no technical means allowing for the mass production and distribution of literary works. Entrepreneurial interests stemming from the reproduction and dissemination of works were just starting to emerge, and social norms were unambiguously in favour of copying.

In ancient times, the profession of a scribe was extremely elitist. ${ }^{53}$ Scribes were held in high esteem and exercised many functions that required a high degree of literacy. In Medieval Europe, the copying of sacred texts was regarded as a metaphysical activity that required complex rituals. ${ }^{54}$ The process of reproducing holy texts was exclusively done in Christian monasteries, which had regular provision for the making of such books (scriptorium). Those who were professionally devoted to the copying of texts were usually working at the services of rulers or religious institutions (temples, monasteries, etc.) who commissioned the reproduction of particular works. At that time, there was no open market for manuscripts. Both scribes and their works were part of either religious or governmental structures, hence belonging to the political system according to the aforementioned model.

It is only in the 11 th century that the first class of professional lay scribes emerged, ${ }^{55}$ travelling from monastery to monastery and treating the reproduction of texts as a mere commercial activity rather than a religious practice. ${ }^{56}$ As the motivation for copying literary works evolved from divine meditation to personal profit, ${ }^{57}$ production moved from monasteries to lay scriptoria and from rural settings to urban centres. This is precisely when the market for creative works emerged, ${ }^{58}$ along with the commercial

\footnotetext{
53 In ancient Mesopotamia, as well as in the ancient Kingdom of Israel, scribes belonged to the highest social elites and enjoyed great esteem. The profession was usually inherited from father to son and limited to the highest social classes. In ancient Egypt the respect towards them was so high that they were considered part of the royal court and were exempted from tax and military obligations. See: Michael Rice , Who's Who in Ancient Egypt, (Routledge, 2001); Peter Damerow, Abstraction and Representation: Essays on the Cultural Evolution of Thinking, (Springer, 1996); Carr David McLain, Writing on the Tablet of the Heart: Origins of Scripture and Literature, (Oxford University Press 2005); Paul Johnson, A History of the Jews, (Phoenix, 1993).

54 The level of complexity of the rituals involved in the process of copying the holy texts could be nowadays illustrated by the procedures followed by sofers - Jewish scribes, who transcribe by hand Torah scrolls and other religious writings, and are one of the last representatives of this profession in the current times. See e.g.: Ray Eric, The Story of a Torah Scroll (Torah Aura Productions, 1986); Kolatch Alfred J., This is Torah (Jonathon David Publishers Inc., 1988); for a general bibliography on the topic see: <http://www.sofer.co.uk/html/sources.htm> accessed 9 April 2014.

55 Rowan Watson, Illuminated Manuscripts and Their Makers (Victoria \& Albert Museum, 2003), p.8.

${ }^{56}$ With the advent of professional lay scribes, books became increasingly produced by lay people who earned their living through the production of manuscripts. Ibidem.

57 Diane E. Booton, Manuscripts, Market and the Transition to Print in Late Medieval Brittany (Ashgate, 2010), p.2.

${ }^{58}$ Although the analysis focuses on the history of the books' market, the same pattern could be reconstructed with regards to other creative works.
} 
interests of different stakeholders. ${ }^{59}$ Relevant for our analysis, this is also when the economic system started to be concerned with the production, dissemination and access to creative works.

By the early thirteenth century, the commercial book trade of many European cities was largely governed by university authorities. ${ }^{60}$ Soon, another category of intermediaries emerged: libraries, who were in charge of hiring scribes and selling completed manuscripts. ${ }^{61}$ Although many of these manuscripts were commissioned by the nobility or the clergy, the production thereof was often justified on mere speculative grounds. ${ }^{62}$ The business of many libraries thus became unpredictable, as there was no guarantee that the costs incurred in the process of production would be adequately covered by market demand. This contingency is crucial for the following analysis: it will be argued that it was, indeed, the commercial risks pertaining to the economic system which irritated the political and legal systems, and which subsequently led to the transposition of the proprietary paradigm to the intellectual realm, so as to protect the economic interests of the middlemen who were facing new challenges ever since the introduction of the printing press.

\section{B. The advent of the printing press}

Gutenberg's invention of the printing press drastically modified the economic, social and cultural landscape in which the book industry operates. Specifically, the development of new printing technologies had a double-edged effect on the interests of intermediaries. On one hand, it allowed for a fast and - for the first time in history - massive reproduction of works that could be achieved at considerably low costs. ${ }^{63}$ This furthered the interests of the middlemen who could increase their profits by selling massive amounts of books, at low cost, to a growing number of potential clients. On the other hand, however, this technology introduced new commercial risks, as potential profits could theoretically be taken by unfair competitors, who could theoretically reproduce the same material, without incurring the costs inherent to the first stage of the publishing process. The new opportunities offered by printing press thus introduced the need to protect and control the production of creative works - a phenomenon that, seen through the lenses of systems theory, can be regarded as a result of the economic system being irritated by technological advances of its surrounding environment.

At that time, in Europe, the interests of publishers (as constituents of the economic system) were mostly compatible with the interests of the governments and the church (two key actors of the political system of that period), who - as an attempt to avoid the dissemination of undesirable content expressing dissent or

\footnotetext{
${ }^{59}$ Yet, as it might be inferred from the historical sources, the commercial interests of those intermediaries were from the very beginning inconsistent, or in some instances even contrary to the interests of the authors themselves. Petrarch in 1363 lamented that the copyists were so eager to make their profit that they reproduced his epic 'Africa' before final correction, Bocaccio was similarly concerned to safeguard his texts until he deemed them ready for circulation. See: Rowan Watson (2003),op.cit. p. 9.

60 Ibidem.

61 Diane E.Booton, (2010), op.cit. p.33. For more detailed information on libraries, see e.g.: Diane E.Booton, The Librarius and Libraire as Witnesses to the Evolving Book Trade in Ducal Brittany in Pecia, (2010), 13.

62 See e.g.: Watson Rowan (2003), p. 11.

63 As it was already mentioned, the libraries with the advent of print resigned from the obsolete services of scribes and illuminators and replaced them with printing machines, themselves at the same time turning from the intermediaries coordinating the work of others into publishers.
} 
criticism of the established government or religion - introduced new forms of controls by means of exclusive licenses to print a specific set of books for a fixed period of years. ${ }^{64}$ These licences (resulting from the structural coupling between the political system and the legal system), as a by-product, strengthened the position of publishers on the market through the introduction of monopoly rights preventing others from printing the same books during that period, ${ }^{65}$ or even just from importing books from abroad. ${ }^{66}$

Hence, the first form of privileges granted over the publication of literary works were monopoly rights granted by royal decree in order to protect publishers against unfair competition, as well as to control (and eventually censor) the publication of all written material. Such a regulatory system, present in most European countries, did not yet amount to modern copyright law - since it had diverse goals and assumed a completely different form. Nevertheless, it could be perceived as the first attempt to regulate the market for intellectual creations through the introduction of exclusive rights which eventually led to the introduction of copyright law. Already under this regime - and long before the introduction of modern copyright law - it was possible to observe the autopoietic operations of the legal system, which - as an attempt to adapt to the changes triggered by the printing press in the creative, political and economic systems - did not actually provide any novel solution (resulting from a structural coupling with the modified environment), but rather applied an old formula (found within its own borders) by gradually extending the proprietary paradigm into the realm of creative works.

The proprietary discourse for intellectual creations first entered the scene in England, around $1590,{ }^{67}$ as literary works began to be regarded as valuable assets that should be protected in the same way as physical property. ${ }^{68}$ This can be seen from the language used in the Stationers' Company's register of printed books ${ }^{69}$ - which clearly illustrates how booksellers started to think of their "copies" or "books" as private property". ${ }^{70}$ This shift in perception is essential for this paper's analysis, for it was exactly when this shift occurred that the proprietary paradigm was first applied in the context of intellectual creations.

Thus, when the Stationers realised that their position on the market was being threatened by technological advances, they relied on the rhetoric of absolute property - understood as a natural right - to secure exclusive rights over intellectual creations. ${ }^{71}$ It should be noted, however, that English publishers initially referred to the property paradigm only in order to justify their own commercial interests, without even

\footnotetext{
64 Hector L.MacQueen, Charlotte Waelde and Laurie T.Graeme, Contemporary Intellectual Property: Law and Policy (Oxford University Press, 2007), p.34.

65 Ibidem.

66 Ibidem.

67 Arber, vol. II, p. 538, quoted after: Lyman Ray Patterson, Copyright in Historical Perspective (Vanderbilt University Press, 1968), p.54.

68 Mark Rose, 'Copyright and its Metaphors' (2002) 50 UCLA Law Review, 1

69 The text in the register evolved from that of "a license to print, to the ownership of copy, to the ownership of a book" Patterson (1968), op.cit.

70 Mark Rose, Authors and Owners: The Invention of Copyright (Cambridge, Mass: Harvard University Press, 1993).

71 In 1643, they published a pamphlet entitled The Humble Remonstrance of the Company of Stationers to the High Court of Parliament in which they specifically referred to the proprietary paradigm, arguing that if "their ancient Right, Propriety of Copies" was no longer available, they would lack "encouragement to make them [their properties] active and alacrious in the service of the state” (emphasis added). See Arber, vol. I, p.586, quoted after: Rose, (1993), op.cit. p. 16.
} 
mentioning the interests of authors. It is only later that, as an attempt to further strengthen their position, the Stationers applied the rhetoric of property also with regard to authors' rights - a rhetoric which has eventually been taken by authors themselves.

In the UK, the first instantiation of modern copyright law - the Statute of Anne - was enacted in 1709, with a view to establish a balance between the interests of authors, users and intermediaries, which in fact assured an adequate equilibrium between all the systems involved in the production, dissemination and access to creative works. The Act introduced the concept of author's rights (as opposed to publisher's rights) and reduced the term of protection to a period of fourteen years, thereby endorsing the idea that copyright substantially distinguishes itself from traditional property rights. ${ }^{72}$

France witnessed similar developments ${ }^{73}$. As royal privileges were reformed to ensure that authors enjoy a perpetual and exclusive right to publish or sell copies of their books, it was held that, were the privilege to be subsequently acquired by a publisher, it would inevitably expire after a specified period of time. ${ }^{74}$ Later, the role of copyright in serving the general interest of the society was further developed after the French Revolution, ${ }^{75}$ as notoriously stated by Le Chapelier: "a published work is by its nature a public property",76, "author's rights are recognised by positive law as an exception to this principle, to compensate an author for his work." 77

Thus - both in England, where copyright was first introduced in common law, and in France, where the first regime of droits d'auteurs was enacted - the initial response to the lobbyists' claims of absolute property was moderate, due to the perceived need to establish a balance between the logics of the creative system, the private interests of authors and publishers in commercializing their works and the general interests of society in promoting the widest dissemination of knowledge and cultural works. Moreover, in both countries, copyright was only meant to provide protection over the expression of a work, as opposed to the underlying facts or ideas. ${ }^{78}$

Over time, notwithstanding the similarities in their goals, the protection of intellectual creations has been

\footnotetext{
72 Symptomatic of this de-propertization of the protection of intellectual and artistic creations is the fact that the initial title of the act was changed from A Bill for the Encouragement of Learning and for Securing the Property of Copies of Books to the Rightful Owners thereof to A Bill for the Encouragement of Learning by Vesting the Copies of Printed Books in the Authors, or Purchasers, of such Copies, during the Times therein Mentioned". See: Rose (1993), p.46.

73 In France, the national debate over the nature of literary property was triggered in 1761 "when a privilege was awarded to the heirs of an author rather than to the author's assignee". See Tylert T. Ochoa, Copyright Duration: Theories and Practice in: Peter $\mathrm{Yu}$, Intellectual Property and Information Wealth $\square$ : Issues and Practices in the Digital Age (Westport Conn.: Praeger Publishers, 2007), p. 141.

${ }^{74}$ While the royal privileges granted to an author were to be inherited by their heirs after the death, they would nonetheless expire if acquired by a publisher - thereby allowing for anyone to apply for a permission simple to print or sell copies of the work. This represents the first attempt, in Europe, to restrict the rights of the publisher as compared to the rights of the author. Ibidem.

75 Ibidem, p. 142.

${ }^{76}$ Report of Le Chapelier to the National Assembly, January 15, 1797 in 7 Le Moniteur Universel.

77 Tylert T. Ochoa (2007), op.cit. p. 142. and Jane Ginsburg, 'A Tale of Two Copyrights: Literary Property in Revolutionary France and America', 64 Tulane Law Review, 64(5), May 1990, p. 1007.

78 This is important to preserve the liberty of individuals to communicate and express themselves freely. Indeed, the ideaexpression dichotomy resolve the potential conflict of the copyright regime with the Lockean provision. In other words, some ideas and facts cannot be removed from the common because there would otherwise not be enough and as good left in common for others afterwards. Hughes, J. (1988). The Philosophy of Intellectual Property. Georgetown Law Journal 7777(287).
} 
implemented differently according to the legal system and the underlying justifications on which it relies.

Most common law countries adopted an utilitarian approach, whereby the copyright system represents a trade-off between the interests of authors and publishers (concerned with the production and the exploitation of their works) and the interests of the public (mainly concerned with the consumption of these works). ${ }^{79}$ While the copyright regime is intended to provide incentives for the former to create new works - by reducing the likelihood of unfair competition - it purports, as well, to preserve the interests of society as a whole, by securing access to a wide range of creative works. Yet, by treating creative works as commodities, the system of copyright mostly operated according to the logics of economics. Seen through the lenses of the systems theory, even if the law tried to adapt to its surrounding environment (by trying to respond to the needs of the creative system, including both the public and creators), it did so by acknowledging mainly the irritations stemming from the economic system, whilst neglecting the specificities of the other systems.

Most civil law countries implemented an author's rights system, whereby authors are granted a series of moral and economic rights over the exploitation of their works. The legal tradition of continental Europe justifies regulation in this sphere of social life by relying on the concept of personality rights in intellectual creations, as developed by Immanuel Kant and Georg Hegel. This conception, which treats the notion of moral rights as the pivot of author's rights protection significantly differs from its commonlaw counterpart, based on a strong proprietary paradigm justified by the mixture of a utilitarian/instrumentalist approach and the rhetoric of absolute property perceived as natural right, as reflected in the philosophy of John Locke. ${ }^{80}$ Given the importance of moral rights in most continental authors' rights regimes, the evolution of the legal system in civil law countries might be perceived as a more appropriate response to the emerging needs of the various constitutive systems involved in the production, dissemination and access to creative works.

The biggest difference between these two approaches lies in the fact that the perception of creative works as "mere commodities" is much more easy to justify in the legal tradition of common-law countries as it is in the case of continental Europe ${ }^{81}$ As a result, the continental regime of author's rights - based on a romantic vision of the author as the holder of moral rights - significantly differs from the more utilitarian conception of copyright law, as the establishment of property rights in intellectual goods.

To begin with, while moral rights have been held to be perpetual in many legal systems, ${ }^{82}$ economic rights have been limited to a specific period of time in order not to excessively restrict the use and production of information. ${ }^{83}$ As for the scope of these rights, a number of exceptions has been introduced to allow for

79 William M. Landes and Richard A. Posner, The Political Economy Of Intellectual Property Law (AEI Press, 2004).

80 See: e.g.: Roberto Garza Barbosa, 'The philosophical approaches to intellectual property and legal transplants. The Mexican Supreme Court and NAFTA Article 1705.' (2009) Houston Journal of International Law, Vol. 31 Nbr 3, June 2009; Neil Netanel, 'Copyright Alienability Restrictions and the Enhancement of Author Autonomy: A Normative Evaluation' (1993) ;24 Rutgers L.J. 347 Justin Hughes, 'The Philosophy of Intellectual Property', (1988) 77 Georgetown Law Journal 287.

81 Robert C. Hauhart, 'Natural Law Basis for the Copyright Doctrine of Droit Moral' (1985-1986) 30 Cath. Law. 53.

82 Susan Liemer, 'Understanding Artists' Moral Rights: A Primer' (1998) Boston University Public Interest Law Journal, Vol. 7, pp. 41-57, 1998.

${ }^{83}$ Carys J.Craig, 'Locke, Labour, and Limiting the Author's Right: A Warning Against a Lockean Approach to Copyright Law' (2002). 28 Queen's Law Journal. 
the unauthorized exploitation of a work whenever that does not harm the economic interests of the copyright holder or it is justified for the general interest of society. ${ }^{84}$ Hence,-just as the copyright system of common law countries refused to incorporate the absolutist proprietary paradigm into the law, the author's rights system adopted in most civil law countries has created a limited monopoly which cannot be regarded as an absolute right.

Notwithstanding the substantial differences between the initial English and French copyright regimes, and their subsequent implementations in other common law and civil law countries, the first legislation in this field should be perceived as the beginning (rather than the end) of a long debate on the role and scope of the proprietary paradigm in regulating the production, dissemination and access to creative works - a paradigm that will be invoked every time technological advances are likely to affect the market for copyrighted goods.

84 W. J. Gordon, 'A Property Right in Self-Expression: Equality and Individualism in the Natural Law of Intellectual Property' (1993) The Yale Law Journal 102 102(7). 


\section{Yesterday: Reproduction technologies}

In the past, given the amount of investments necessary to acquire the technology of the printing press, only a few institutions were able to purchase the machineries and technical equipment for the publication of literary works. Copyright law was, initially, only concerned with the operations of a few competing publishers, which were increasingly motivated by large commercial interests.

The industrial revolution had a considerable impact on the social, economic and cultural structures of society. The advent of an industrial society came along with the establishment of new values associated with mass-production and mass-consumption of commodities which, in turn, had important implications on the economic growth and cultural development of society. ${ }^{85}$ Most importantly, the industrial revolution has led to what we refer nowadays as the capitalist mode of production - characterized by the concentration of means of production in the hands of a few so as to achieve larger economies of scale and therefore maximize profits. ${ }^{86}$

Competition within the industry and the constant race for profits has led to the development of new media and devices (e.g. television, video recorders, radio receivers and transmitters, etc) generating new market demand by encouraging new forms of consumption. In this context, creative works rapidly became a great source of interest for the industrial world, driven by the new opportunities for innovation in information and communication technologies. Thanks to the widespread adoption of these new technologies, creative works rapidly caught the attention of new players, attracted by the potential profits associated with the commercialization of these works. Radio and television broadcasting, the process of publishing or advertising, along with the various operations of the recorded music industry, are only a few examples of how profits can be extract by turning creative works into mere commodities. ${ }^{87}$ This, along with the development of sophisticated technologies enabling faster, cheaper and more accurate reproductions of creative works, promoted the emergence of a new sector - the so-called "creative industries" (or "cultural industries" $)^{88}$ - composed of a variety of "intermediaries" mainly concerned with the reproduction and distribution of copyrighted works. ${ }^{89}$ Yet, the focus of these intermediaries is not the production of new works, but merely the reproduction and dissemination of physical "copies". Through the provision of cultural goods or services (often involving works protected by intellectual property rights), they establish a link between the authors - who create new works - and the users - who consume these works. Seen through the lenses of the systems theory, intermediaries ultimately belong to the system of economics which "speaks the language of prices".

\footnotetext{
${ }^{85}$ Ronald Inglehart, Culture Shift in Advanced Industrial Society (Princeton University Press, 1989).

${ }^{86}$ Ronald Max Hartwell, The Industrial Revolution and economic growth (Methuen Young Books, 1971).

${ }^{87}$ Howard Davis and Richard Scase, Managing creativity: the dynamics of work and organization (Lavoisier, 2001).

88 The two terms appear to be used interchangeably to refer to the same thing, although they differ in terms of their connotations. See Nicholas Garnham, 'From cultural to creative industries: An analysis of the implications of the "creative industries" approach to arts and media policy making in the United Kingdom' (2005) International Journal of Cultural Policy, Volume 11, Issue 1.

${ }^{89}$ With the advent of the information society, the creative industries are having an ever stronger impact on the global economy. For instance, in the UK the creative industries are growing at twice the rate of the economy as a whole, and they contribute to more than four percent of the domestic economy, employing around one and a half million people and generating over sixty billion pounds a year. M. Blythe 'The Work of Art in the Age of Digital Reproduction: The Significance of the Creative Industries' (2001) International Journal of Art \& Design Education 20(2).
} 
New business models emerged, for the most part designed around the production and distribution of physical media - whose value ${ }^{90}$ is ultimately derived from the intangible work they incorporate: ${ }^{91}$ books, videotapes, vinyls, magnetic tapes, etc. all belong to this category. The cultural industry thus relies on copyright law to obtain profits from the distribution of "physical copies". Whether profits are obtained through the sale, the rental or the broadcasting of copyrighted works, all of these business models rely on the mass-production and mass-distribution of cultural commodities, which - through their market value will remunerate authors, publishers, or other content producers.

It is important to note, however, that this model conceals an important drawback. Given the considerable costs involved in the production of new works, as opposed to the small variable costs required for the reproduction thereof, most of the market players operating in the cultural industry have an incentive to produce a large number of copies for a limited number of works in order to maximize the economies of scale; a situation which is ultimately detrimental to cultural diversity. This is precisely that conflict between the economic system and the system of creativity that has led to a growing divergence between the economic interests of commercial right holders or intermediaries, and the interest of authors or the public at large.

Driven by principles of innovation and profit-maximization, many of these intermediaries have become key economic actors with a strong influence in the global economy. Given the significant role played by copyrighted works in the everyday operations of these large corporations operating in the cultural sector, copyright law has progressively been taken over by the lobbying of the creative industries seeking to maximize their profits.

Given the considerable amount of investments necessary to engage in the production and distribution of physical media, intermediaries have maintained for many years a de facto monopoly over the production and reproduction of many creative works. Yet, the advent of new reproductive technologies allowing anyone to produce a large number of copies at marginal costs and without significant quality-losses has put this model into jeopardy - eventually spurring the need for new developments in copyright law.

Indeed, these technological advances had a similar double-edged effect on the commercial interests of intermediaries within the cultural industry, as the invention of the printing press had on the interests of publishers. On the one hand, the operations of these intermediaries have been greatly facilitated by the advent of new technologies (such as photocopiers, tape-recorders, video-recorders, etc.) enabling creative works to be mass-produced in a very short time and at very low cost. On the other hand, however, the same technology enabled others to reproduce a large number of works with minimal investment as regards the time and money involved in the process.

This time, however, technology was enabling end-users - and not only professional competitors - to reproduce these works. In fact, the mass-production and widespread deployment of affordable recording equipments allowed for cheap reproduction techniques to be employed by common users with no specific technical skills. Thanks to these new technologies, the making of unauthorized copies was no longer

\footnotetext{
90 Value in this context does not refer to the monetary value - i.e., the price that the public is willing to pay - but rather to the perceived value of the intangible work - which is generally perceived as greater than the value of the medium per se.

91 The distinction between the work and the medium is an essential aspect in intellectual property rights and was already recognized in ancient Roman law. See, e.g. the distinction between res corporales and res incorporales in Russ VerSteeg. 'The Roman Law Roots of Copyright' (2000) 59 Md. L. Rev. 522.
} 
limited to commercial competitors operating in an industrial setting; more and more copies were actually being made at home, by end-users and primarily for private purposes.

Yet, given the costs of the operation and the economies of scales involved in the process, the large-scale distribution of copies was still limited to a few large players operating with commercial motives. The interests of intermediaries and other right holders were nonetheless being challenged by a new category of infringers: end-users - who, although not directly in competition with the creative industries, were now able to reproduce creative works without having to go through the official supply chain. According to systems theory, this pattern might be regarded as an irritation to the economic system by emerging developments within the systems of creativity and technology.

Thus, as they did in the past - every time they felt that their interests were being endangered by the influence of a new technology - right holders initiated a new wave of lobbying with a view to acquire a greater degree of control over the copyrighted material they own. Once again, they resorted to the rhetoric of absolute property in order to strengthen the proprietary paradigm inherent to copyright law so as to preserve their financial interests, often at the costs of compromising the general interests of society. Seeing their role as "gatekeepers" 92 being threatened by technological advances, publishers and other intermediaries in the cultural industry advocated for greater control over all uses that could be made of a work. They reclaimed control over the private sphere of users, arguing that both the manufacturers or retailers of technological devices used for massive reproduction, and the individual users who relied upon them to make copies should be held liable of copyright infringement. ${ }^{93}$

Yet, copyright law was never intended to grant absolute control over the exploitation of a work. Over the years, the copyright regime never provided protection against private consumption by individuals - which was always perceived as being beyond the scope of the copyright - thus not requiring prior authorisation to be obtained. Indeed, the concept of "private use" was so obviously accepted by European copyright scholars that it was not even mentioned by earlier copyright acts. ${ }^{94}$ Specific limitations for private use only appeared in the beginning of the 20th century. ${ }^{95}$

Hence, the legal system resisted the lobbying, maintaining a balanced approach by establishing a trade-off between (a) the interests of authors and right holders in protecting their works against illegitimate uses or unfair competition, and (b) the interests of the public in securing a legitimate right to access and reuse

\footnotetext{
92 Introduced by Kurt Lewin in 1947, the "gatekeeper" in a social system has been defined as the one who decides which commodities may enter the system. Today, the concept has been transposed in the digital world, where the intermediaries from the cultural industry have acquired the role of "gatekeepers" to the extent that they can decide what kind of content will be produced and made available to the public through the traditional supply chain. See Thomas F. Cotter 'Some observations on the Law and Economics of intermediaries' (2005) Michigan State Law Review, Legal Studies Research Papers. Yet, according to Neelie Kroes, vice president of the European Commission in charge of the Digital Agenda: "No historically entrenched position guarantees the survival of any cultural intermediary. Like it or not, content gatekeepers risk being sidelined if they do not adapt to the needs of both creators and consumers of cultural goods." Neelie Kroes 'A digital world of opportunities, Forum d'Avignon - Les rencontres internationales de la culture, de l'économie et des médias', November 2010.

93 G. Gentz, 'Überspielungsfreiheit zum persönlichen Gebrauch?', GRUR 11/1952, pp. 495, quoted after Hugenholtz et al. op.cit. p.10.

94 P.B. Hugenholtz, L. Guibault, S. van Greffen, The Future of Levies in a Digital Environment, $<$ http://www.ivir.nl/publications/other/DRM\&levies-report.pdf> accessed 24 June 2013.

95 Exemptions for the reproduction of a work in a limited number of copies for the purpose of private practice, study or use of the person making the copies appeared for the first time in early 1900 versions of Dutch and German copyright statutes, and a provision concerning a private use in French law was introduced as late as in 1957. See: B. Hugenholtz, L. Guibault, S. van Greffen), op.cit. p. 10.
} 
works belonging to the cultural heritage.

In many countries, the equilibrium between the different logics stemming from all relevant systems involved in the production, dissemination and access to creative works has been re-established by reforming the law so as to leave the unauthorized reproduction of copies for personal and non commercial purposes outside of the realm of copyright infringement, while nonetheless implementing a framework for mandatory royalties (or levies) to ensure that proper compensation is given. ${ }^{96}$ The mechanism of levies incorporates a compulsory tax into the price of any product or device that is likely to be used for the making of private copies, and provides for a redistribution scheme according to which every right holder should receive a fair level of compensation for any potential loss of revenues deriving from private copying. This, again, allows for the potential reestablishment of the equilibrium between the systems of creativity, economy and technology.

Such a mechanism was first introduced in Germany, as a consequence of two decisions of the German Federal Supreme Court (the Grundig Reporter case ${ }^{97}$ of 1955 and the Personalausweise case ${ }^{98}$ of 1964) and then spread throughout the rest of continental Europe. The reasons for introducing the mechanism of levies combined with the earlier private copying exceptions in Europe were to balance the rights of both users and right-holders as required by the three-step test set out in the Berne Convention, which establishes the conditions for any limitations of the reproduction right. ${ }^{99}$

The framework-rapidly spread all over Europe - except in the UK, where the limits of the monopoly granted under copyright law were more explicitly acknowledged - e.g. in the case of Amstrad Consumer Electronics plc $v$ The British Phonograph Industry Ltd (1986), where the court held that the power of the copyright owner can be limited for the sake of supporting technological innovation. ${ }^{100}$ (Following the logic of the systems analysis, this ruling may be seen as an attempt to balance the needs of the economic system with the system of technology).

Accordingly, the legal system managed - to some extent - to balance the logics of different systems without necessarily favoring one over the other. While the mechanism of levies acknowledges and endorses the widespread social norms favouring the reproduction of works for non-commercial purposes, it does effectively compensate right holders for any of the losses derived from private copying. Yet, to the extent that it qualifies as free-riding or unfair competition, the reproduction of copyrighted material with a commercial motive (e.g. by people selling pirated copies of CD's in the streets) or the large-scale dissemination thereof (e.g. by commercial counterfeiters) remains punishable under the law.

\footnotetext{
96 See: Article 5(2) of the European Copyright Directive 29/2001/EC: "Member States may provide for exceptions or limitations to the reproduction right [...] (b) in respect of reproductions on any medium made by a natural person for private use and for ends that are neither directly nor indirectly commercial, on condition that the right holders receive fair compensation." Most countries of the European Community have implemented such an exemption by the means of a levy system (except for the UK which does not allow for private copying). The USA and Canada also introduced a particular system of levies, but only with regards to audio recording media (See, respectively, the US Audio Home Recording Act of 1992 and sections 81-82 of the Canadian Copyright Act).

${ }^{9} \mathrm{BGH}, 24$ June 1955- Aktz.: I ZR 88/54 (Mikrokopien) in GRUR 11/1955.

98 BGH, 29 May 1964 - Aktz.: Ib ZR 4/63 in GRUR 02/1965.

99 J. Reinbothe, Private Copying, Levies and DRMs against the Background of the EU Copyright Frameworks, DRM Levies Conference, 8th September 2003, <http://ec.europa.eu/internal_market/copyright/documents/2003-speech-reinbothe_en.htm> accessed 20 June 2013.

100 In the light of this analysis, it is worth mentioning that the UK did not introduce a levy system as a result of the pressure from tape manufacturers and consumer groups. See: Hugenholtz et al. op.cit.12.
} 


\section{$\underline{\text { V. Today: Digital technologies }}$}

Today, another technological revolution is taking place. Internet and digital technologies facilitate the production, reproduction, and distribution of digital works - which, thanks to the deployment of modern peer-to-peer technologies, can be disseminated on a global scale without any significant investment. These technologies have spurred the development of new online practices which are considered by some to be endangering the interests of right holders and intermediaries: not only do they encourage end-users to engage in the mass reproduction of copyrighted material, but they also allow for the mass distribution thereof.

Once again developments within the technological system led to the coevolution of the system of creativity which in turn irritated the economic system. As the medium itself becomes non-rival, users do no longer need to rely on any intermediaries to intervene in the supply chain. Hence, even though they generally operate outside of the commercial sphere, individual users - rather than potential competitors are now the biggest challenge to the protection of right holders' economic interests.

\section{A. Copyright reform for the digital environment}

To be sure, the advent of digital technologies significantly affected the system of social norms adopted by the public. Internet and other communications technologies created unprecedented opportunities to make creative works available to everyone by disseminating digital works on a global scale, regardless of their legal status. What was once only a possibility for a few, turned into a global need - or a must. The potential of digital technologies changed the attitude of end-users as regards what should be legally or legitimately allowed - leading to the assumption that legal rules should be adjusted in order to enable users to benefit from the new opportunities of the digital world.

Yet, the same technological changes that motivated end-users to articulate their claims for free culture and broader access to information were simultaneously used by copyright holders to advocate for stronger protection. Once again, therefore, the legal system was facing the lobbying of the cultural industry, composed mainly of intermediaries attempting to enforce the paradigm of absolute property in order to protect their economic interests.

This time, however, the absolute-property campaign successfully managed to change the face of copyright law. Right holders successfully advocated for an extended term of protection ${ }^{101}$ and a reduction in the number of copyright exemptions, ${ }^{102}$ while further restrictions - often going beyond the scope of

\footnotetext{
${ }^{101}$ Copyright terms of protection were extended in the European Union to 70 years from the death of the author, what changed the earlier threshold set by the Berne Convention requiring only 50 years of protection post mortem auctoris by the introduction of the Council Directive 93/98/EEC of 29 October 1993 harmonising the term of protection of copyright and certain related rights, which was later replaced by Directive 2006/116/EC of the European Parliament and of the Council of 12 December 2006 on the term of protection of copyright and certain related rights. In the United States the Copyright Term Extension Act (CTEA) of 1998 (also known as the Sonny Bono Copyright Term Extension Act, Sonny Bono Act, or as the Mickey Mouse Protection Act) extended copyright protection terms to life of the author plus 70 years and for works of corporate authorship to 120 years after creation or 95 years after publication, whichever endpoint is earlier.

102 A different regime of exemptions has been introduced for technologically protected copyright works (see WIPO Copyright Treaty, article 10 and WIPO Performances and Phonograms Treaty, article 16; as implemented in the European Community by the Information Society Directive article 5, which proposes one mandatory exemption together with a list of optional limitations that the
} 
copyright protection - have been subsequently implemented through private ordering by means of contractual provisions and the deployment of Digital Right Management (DRM) technologies. ${ }^{103}$ This, along with the introduction of an additional layer of protection against the circumvention of technological measures of protection ${ }^{104}$ allowed for copyright owners to determine exactly what can or cannot be done with a work (thus acquiring control over the mere consumption of that work) and contributed to the growing tendency of transferring copyright regulations from the realm of private law into the realm of criminal law.

While the law has indeed been reformed to meet the growing demands of rightholders (which in this case were mainly intermediaries), the legislators did not properly take into account the repercussions that these reforms might have on the interests of end-users. As opposed to their expectations of increased freedom and autonomy, end-users were faced with stricter legal rules constraining both the access and the reuse of information, along with the proliferation of "secondary remedies" 105 precluding the use of copyrighted material even against legitimate or "fair uses".

This shift in the objectives of the law can perhaps be linked to the fact that the international law-making process was moved from the scope of the World Intellectual Property Organisation - the UN Agenda specialising in intellectual property law - to the World Trade Organisation, whose mission is "aimed at reducing obstacles to international trade". ${ }^{106}$

Indeed, not only did the Trade Related Aspects of Intellectual Property Rights (TRIPS) Agreement "dramatically expand[..] intellectual property protection standards" ${ }^{, 107}$ worldwide, it also introduced for the first time - intellectual property regulations into the international trading system, based on the idea that creative works should be treated equally to all other types of commodities. It appears, thus, that the proprietary paradigm of copyright law degenerated into an absolute right, disrupting the delicate balance that the legislator had been struggling to preserve over the years. This shift between the regimes is symptomatic of a failure of copyright law to adapt properly to its new environment, which has been significantly modified by digital technologies. Indeed, throughout its evolution, the legal system responded mainly to the stimuli stemming from the economic system, whilst ignoring the logic of the other systems, especially the creative one. We regard this as a failure of the copyright system to meet the expectations of the constitutive elements of its surrounding environment. By

member states can implement in their national legislation, subject to the qualification of article 6(4) according to which no measures needs to be taken to ensure that the exemptions are made available to the users whenever voluntary measures such as private agreements have been undertaken between right holders and the other parties concerned; and as implemented in the United States by the DMCA section 1201(d) to 1201(i), which establishes a regime of limitations much less flexible than the system resulting from the application of the fair use doctrine of the US Copyright Act of 1976, 17 U.S.C. § 107.

103 Digital Rights Management technologies is a class of access control technologies that are used by hardware manufacturers, publishers, copyright holders and individuals with the intent to limit the use of digital content and devices after sale. DRM is any technology that inhibits uses of digital content that are not desired or intended by the content provider. Definition quoted after Wikipedia, <http://en.wikipedia.org/wiki/Digital rights management> accessed 20 June 2013.

104 Requirement for anti-circumvention laws was globalised in 1996 with the creation of the WIPO Copyright Treaty, which requires the enactment of anti-circumvention laws prohibiting the circumvention of technological measures for the protection of copyright works as well as the production and the distribution of circumventing devices (see WIPO Copyright Treaty, articles 11,12 and WIPO Performances and Phonograms Treaty, articles 18, 19; as implemented in the European Community by Directive 2001/29/EC of the European Parliament and of the Council of May 22, 2001 on the harmonization of certain aspects of copyright and related rights in the information society (hereinafter the Information Society Directive), articles 6, 7; and as implemented in the United States by The Digital Millennium Copyright Act of 1998 (hereinafter the DMCA), section 1201

${ }^{105}$ Ysolde Gendreau, 'The Image of Copyright', E.I.P.R., 2006, 28 (4), 209-212, p. 210.

105

106 See: http://www.wto.org/english/thewto e/whatis e/wto dg stat e.htm.

${ }^{107}$ Laurence, R. Helfer, 'Regime Shifting in the International Intellectual Property System' (2009) 7 Perspectives on Politics 39-44 . 
trying too hard to "remain the same" (i.e. to preserve the former status quo), copyright law has actually changed the rules of the game - thereby introducing a critical conflict between legal norms (the copyright regime) and social norms (authors and users' practices within the creative system) as regards the production, dissemination and access to creative works.

\section{B. The mismatch between legal norms and social norms}

The extensive protection of copyright holders' interests - introduced at the expense of the public's general interest - has led to the establishment of problematic behaviours associated with the bad perception of copyright law. In fact, the extension in the scope of copyright protection not only went against the new expectations that emerged with the advent of digital technologies (allowing for decentralized production and dissemination on a global scale), but also went against the entrenched social norms favouring private use $^{108}$ - increasingly constrained by technological means (e.g. DRM systems) and legal contraptions (restrictive EULAs) purposely implemented by copyright holders.

This is when the place of copyright law in the public discourse drastically changed. Before the Internet revolution, as perceptively noticed by Ysolde Gendreau "copyright law was perceived, even by those in the legal profession, as an arcane and highly specialised area of the law. Its status as an intellectual property right that pertains to the arts helped to cultivate an aura of exclusivity around it." 109 Nowadays, the situation has radically changed, as copyright law has become one of the mostly discussed legal issues around the world - an issue that is often taken up by laymen. However, as Gendreau correctly notes, "this heightened visibility has not translated itself into a greater degree of popularity." copyright law is nowadays experiencing a critical drop in reputation.

Indeed, as the impact of copyright regulations in the information society is becoming more and more relevant to people's everyday life, copyright's stifling effect on creativity has entered the public discourse. The negative image that the copyright regime has acquired in the public opinion is informed, inter alia, by the following issues:

\section{The supremacy of intermediaries}

One important issue is the perceived removal of the creative author from the overall system - increasingly controlled by large corporations and collecting societies, whose profits are often perceived as being illegitimate. While many opponents of the copyright regime do actually sympathise with authors (and are generally willing to support them), ${ }^{111}$ they do not, however, believe that the law serves the interests of creators, but rather perceive it as a means to further the interests of intermediaries, at the detriment of

\footnotetext{
108 At least in countries with continental law that introduce private personal use clause. British copyright system for instance does not introduce the institution of the private copy so the expectations of the British end-users might considerably differ from their counterparts in continental Europe. On the other hand, however, the Hargreaves Report recommended the introduction of a private copying exception for the Internet, partly because of social norms demanding it. <www.ipo.gov.uk/ipreview-finalreport.pdf> accessed 20 June 2013.

109 Ysolde Gendreau, op. cit. p. 209.

110 Ibidem, p. 210.

111 The increasing popularity of the funding platforms for creative projects like www.kickstarter.com is the best example of the fact that many people are willing to pay to the original authors outside the framework of copyright law for getting access to their works.
} 
authors and society as a whole. ${ }^{112}$

The negative image of copyright law is perceived as the outcome of unregulated and unbalanced lobbying by big corporations. ${ }^{113}$ This is recognized by a variety of authors' and performers' representatives, ${ }^{114}$ who advocate for "removing the barriers between the artists and their fans," ${ }^{115}$ claiming that "copyrights should be owned by creators rather than corporations" ". Applying the reasoning of the systems theory, this 'hostile' attitude can be seen as a natural reaction of the creative system responding to the economic system trying to "monopolise" the realm of production, distribution and access to creative works by imposing its own logic through the operations of the political system (lobbying of the industry) .

\section{Asymmetries of power}

The negative picture of the copyright regime also emerges from the atmosphere of secrecy, conspiracy and hatching that is found in the negotiation processes of both international treaties and domestic agreements for copyright enforcement. ${ }^{117}$ The negotiation of the Anti-Counterfeiting Trade Agreement (ACTA) is an example of the opaqueness which characterizes the law-making process in the field of international intellectual property law. While the negotiations were held in secret, some important documents were leaked in May 2008, as a result of which leading civil liberty advocates and nongovernmental organizations (NGOs) from all over the world urged for more transparency and inclusiveness in the proceedings, ${ }^{118}$ in vain. The NGOs regarded the lack of transparency as the sign of

112 This picture is further reinforced by the fact that most intermediaries (distributors and collecting societies) are the most active lobbyists in the recent debates concerning the reform of copyright law.

${ }^{113}$ The fight against excessive copyright regulations is to some extent related to the recent initiatives of the Occupy and Indignados movements, driven by similar ideals, but more concerned by denouncing the excessive power granted to multinational corporations to protect their financial interests at the expense of the general interest. Some authors even claim that Free Culture and Digital Commons Movement played "an important role in the rising and shaping" of the Indignados movement in Spain. See: M. Fuster Morell, 'The Free Culture and 15M Movements in Spain' (2012) 'Composition, Social Networks and Synergies, Social Movement Studies: Journal of Social, Cultural and Political Protest,1-7. The Open Access movement, known also as the Free Culture and Digital Commons Movement, and Occupy and Indignados movements alike might be also perceived as a fraction of the wide, transnational movement of the commons, "characterised as the struggle of local communities to reclaim access and governance of resources from collusive state and market actors" See: Saki Bailey and Ugo Mattei, 'Social Movements as Constituent Power: The Italian Struggle for the Commons' (Spring 2013) Indiana Journal of Global Legal Studies. In such an approach movements reclaiming the commons and fighting against the negative effects of economic globalisation could be classified into two types: 1. more traditional fight over tangible resources e.g. water, land, 2. more recent struggle over intangible resources e.g. knowledge, art. The battle with strong proprietary vision of copyright fits within the latter type.

114 The Featured Artists Coalition (http://thefac.org)- led by the board of directors recruited from the most famous British performers like Annie Lennox, Radiohead or Pink Floyd - is an example of creators and artists unsatisfied with the current copyright regime and advocating for a reform in the industry.

115 See: <http://thefac.org/about/> accessed 24 June 2013.

116 2013

117 Such agreements are often signed between the ISPs and the representatives of copyright holders or the collecting societies. They are usually negotiated in secret, and information about them most often leaks to the public through the unofficial sources causing discontent or even indignation on the part of the general public. A good example of such an agreement is the Polish draft agreement "On cooperation and mutual assistance in the protection of intellectual property rights in the digital environment" negotiated between the representatives of collecting societies and ISPs under the auspices of the Polish Ministry of Culture, which was finally blocked by the NGOs claiming it would endanger the fundamental right to privacy.

118 The initial documents were drafted without the participation of civil society groups and representatives of the developing

${ }^{118}$ countries. In the open letter signed by numerous citizens groups and consumers associations such as Consumers Union, Electronic Frontier Foundation, Essential Action, IP Justice, Knowledge Ecology International, Public Knowledge, Global Trade Watch, U.S. Public Interest Research Group, IP Left (Korea), Australian Digital Alliance, The Canadian Library Association, Consumers Union of Japan, National Consumer Council (UK) and Doctors without Borders' Campaign for Essential Medicines, the representatives of the advocacy groups wrote: "We are writing to urge the negotiators of the Anti-Counterfeiting Trade Agreement (ACTA) to immediately publish the draft text of the agreement, as well as pre-draft discussion papers (especially for portions for 
negotiating parties' bad intentions, and pointed to the negative influence that such secrecy had on the general public's perception of the drafted documents. ${ }^{119}$ These concerns were shared by the European Parliament, ${ }^{120}$ who called on the European Commission to "immediately make all documents related to the ongoing international negotiations on the Anti-Counterfeiting Trade Agreement (ACTA) publicly available" in its resolution of 10 March $2010 .{ }^{121}$

Although many right holders justify the opaqueness of such arrangements by fact that trade consultations generally only involve commercial players, ${ }^{122}$ the situation drastically changed with the advent of Internet and digital technologies. What used to be a law concerning a limited number of professionals turned into a law that could significantly affect the everyday life of the general public and impinge upon users' fundamental rights, such as the right to privacy and freedom of expression.

The inclination to conceal also originates from the presumption that the protection of right holders' interests (especially intermediaries on the market for intellectual goods) necessarily involves a fight: this marks the beginning of the so-called "copyright war" between end-users on one side and the cultural industries on the other. Started in the U.S., the copyright war soon spread all over the world, with a series of regulations aimed at fighting copyright infringement in the digital environment by means of criminal proceedings against end-users (see e.g. the French HADOPI law). ${ }^{123}$

From a systems theory perspective, these asymmetries of power can be understood as the economic system structurally coupling with the political system (through lobby) and irritating the copyright system in order to further its own interests, at the detriment of the other constitutive elements of the ecosystem.

\section{Criminal prosecution of end-users}

Another factor that contributed to ruining the already tarnished image of copyright law is the tendency to direct criminal sanctions against individual infringers - as opposed to large-scale infringers illegitimately redistributing copyrighted material with a commercial motive.

Indeed, since the mid 90s', an aggressive litigation campaign emerged, targeting not only commercial entities but also ordinary citizens, who started to perceive the enforcement of copyright law (which

\footnotetext{
which no draft text yet exists), before continuing further discussions over the treaty. We ask also that you publish the agenda for negotiating sessions and treaty-related meetings in advance of such meetings, and publish a list of participants in the negoiations." See at: http://www.wired.com/images_blogs/threatlevel/files/actaletter.pdf. [Accessed on 31.01.2013].

119 The lack of transparency in negotiations of an agreement that will affect the fundamental rights of citizens of the world is fundamentally undemocratic. It is made worse by the public perception that lobbyists from the music, film, software, video games, luxury goods and pharmaceutical industries have had ready access to the ACTA text and pre-text discussion documents through longstanding communication channels." Ibidem.

${ }^{120}$ European Parliament resolution of 10 March 2010 on the transparency and state of play of the ACTA negotiations, available at: http://www.europarl.europa.eu/sides/getDoc.do?type=TA\&reference=P7-TA-2010-0058\&language=EN\&ring=P7-RC-2010-0154 [Accessed on 31.03.2014].

${ }^{121}$ For more details on "negative image of copyright law" see: Katarzyna Gracz, 'On the Role of Copyright Protection in the Information Society. Anti-ACTA Protests in Poland as a Lesson in Participatory Democracy' (2013) Journal of Intellectual Property, Information Tech

121 nology, and Electronic Commerce Law, 4, pp. 22-36

122 A good example of such an explanation is the position of the European Commission issued in November 2008 in which it stated as follows: "It is alleged that the negotiations are undertaken under a veil of secrecy. This is not correct. For reasons of efficiency, it is only natural that intergovernmental negotiations dealing with issues that have an economic impact, do not take place in public and that negotiators are bound by a certain level of discretion." See: European Commission, "Fact Sheet: Anti-Counterfeiting Trade Agreement" 23 October 2007 (Updated November 2008) <trade.ec.europa.eu/doclib/docs/2008/october/tradoc_140836.11.08.pdf.> accessed on 21.05.2013.

122

123 The official name of the so called "HADOPI Law " in French is "Loi n 2009-669 du 12 juin 2009, Projet de loi favorisant la diffusion et la protection de la création sur Internet".
} 
shifted from the civil to the criminal realm) mostly as an unpredictable weapon pointed against them. ${ }^{124}$ It is, indeed, inadequate to employ the same aggressive strategies used to discourage commercial competitors from benefiting from the unauthorised distribution of copyrighted materials with regards to end-users - who, as opposed to commercial competitors, represent the actual target from which the creative industries can derive their profits.

The trend towards stronger copyright enforcement - as illustrated by the cases of Pirate Bay ${ }^{125}$ and Richard O'Dwyer ${ }^{126}$ - has been perceived, by many, as a form of American neocolonialism: ${ }^{127}$ a means for American corporations to enforce their rules outside of the US territory. ${ }^{128}$

Similar trends can be observed in the linguistic realm, as copyright holders (mostly intermediaries) began to describe end-user copyright infringement as "piracy" - a notion that was so far reserved for commercial entities. ${ }^{129}$ This contributed to blurring the borders between end-user infringement and counterfeiting (i.e. large-scale reproduction and distribution by commercial actors) ${ }^{130}$ - which led, eventually, to the trivialisation of the concept of piracy as it is perceived by the general public. ${ }^{131}$

Indeed, the copyright war actually encouraged the emergence of whole communities of people advocating for free culture and freedom of information - and who contribute to further diminishing the respect for copyright norms. These communities also began to develop new strategies to oppose the current evolution of the copyright regime - such as the Creative Commons initiative ${ }^{132}$ which proposes a system of alternative licenses for authors willing to waive the rights granted by default under the law.

Through the lenses of systems theory, such initiatives might be regarded as an attempt by the creative system to structurally couple with the legal system in order to-reacquire control over the areas that had been formerly absorbed by the economic system.

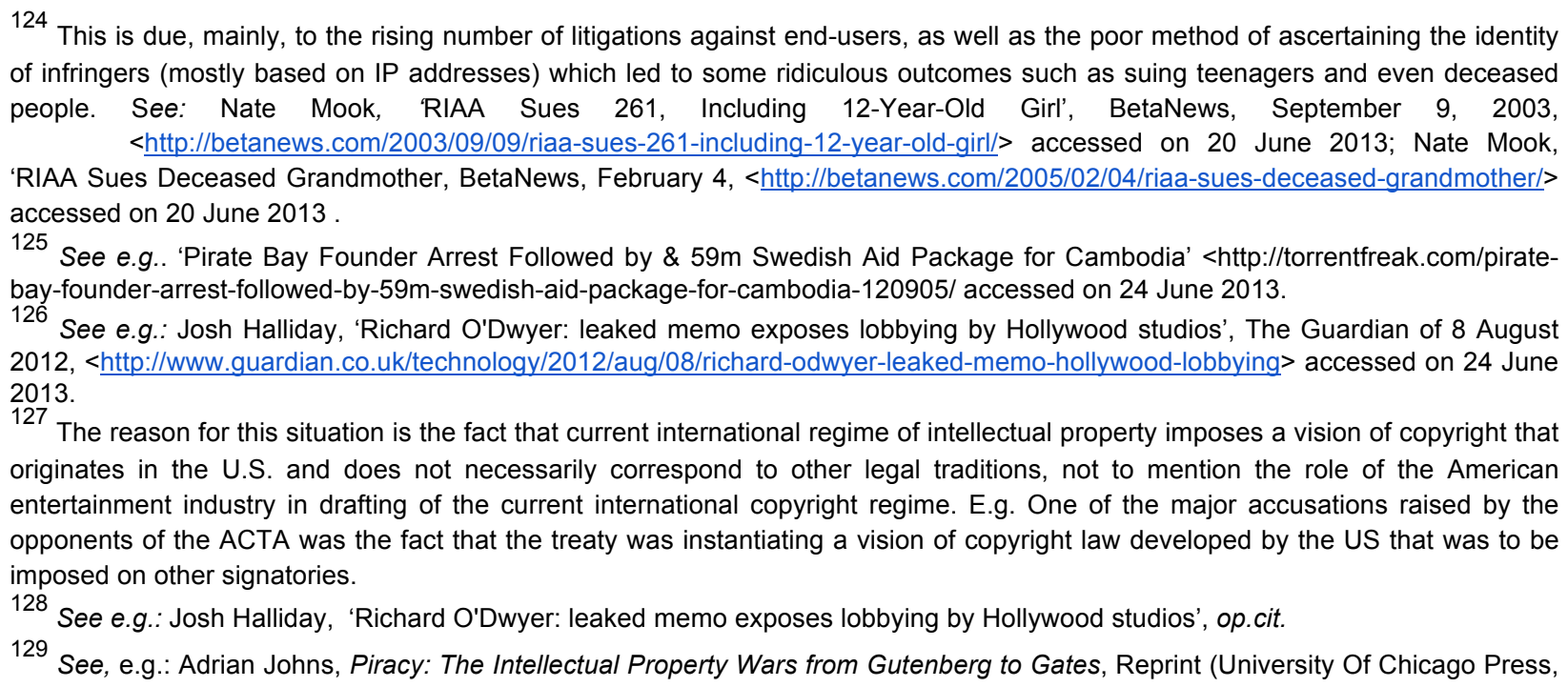
2011).

130 Jane C. Ginsburg, 'Essay - How Copyright Got a Bad Name For Itself', SSRN eLibrary <http://papers.ssrn.com/sol3/papers.cfm?abstract_id=342182> accessed 24 June 2013, p.5.

131 In terms of prosecution, there is, indeed, nowadays, hardly any difference between suing innocent teenagers or non-profit infringers and bringing criminal proceedings against entities whose commercial activity is ultimately based on the non-authorised mass reproduction and distribution of the copyrighted material.

132 Creative Commons is a non-profit organization headquartered in Mountain View, California, United States devoted to expanding the range of creative works available for others to build upon legally and to share. More information available on $<$ www.creativecommons.org> accessed 24 June 2013. 
All the conditions described above created a negative image of copyright law, deepening the gap between legal rules (established by the legal system) and social norms (produced by the creative system), and thereby increasing the costs of compliance with the law. With the advent of digital technologies, the delicate equilibrium of copyright law - which established a balance between the different systems or subsystems involved in the production, dissemination and access to creative works - has eventually been disrupted. Copyright law was originally designed as a means for professionals (be them artists, publishers, or other intermediaries) to prevent other professionals from free-riding over their own investments. Today, however, in addition to it being used as a mechanism to fight against unfair competition, the copyright regime is also (and mainly) being used to fight against a large number of end-users, whose social norms are becoming increasingly incompatible with the law. Hence, as the law goes counter the everyday practices of end-users (who are regarded as criminals), it must ultimately be enforced against the majority of the population, as opposed to a small portion of commercial infringers. The failure of copyright law to regulate social dynamics becomes, consequently, much more apparent. This failure may ultimately be seen as resulting from the improper evolution of the legal system, which favoured the stimuli stemming from the economic and political systems over those of the technological and creative ones.

\section{Conclusions}

While copyright law has been, for many years, an effective body of law, constantly evolving to adapt to on-going technological advances and social or organisational changes, today, the copyright regime seems to have entered into a crisis, as the original rationale ${ }^{133}$ of the law has progressively been disrupted by the advent of Internet and digital technologies, and the radical change in contingencies that came along them.

The article has shown that the main reason for the current inefficiency of copyright law in regulating social dynamics within the digital landscape results from its failure to maintain a proper balance between the different logics of all the constitutive elements of the ecosystem in which copyright law operates.

It was argued, in particular, that this equilibrium had originally been lost due to an improper extension of the proprietary paradigm (a paradigm which emerged through structural coupling between the legal system and the economic system, and, as such, favoured the economic logic over the logics of other relevant systems) as implemented within the realm of intellectual property law.

The situation became even worse with the advent of Internet and digital technologies, which radically changed the rules of the game by reducing the asymmetries of power between the public and the creative industries, while encouraging end-users to assume a more active role in both the production and the consumption of information. On the one hand, users increasingly contribute to enriching the content of the websites they visit (e.g. by means of user reviews, comments or feedback) and often participate directly to the production thereof (e.g. in the case of user-generated-content). This trend has been described by Lawrence Lessig as an illustration of the "read-write" nature of the Internet - as opposed to

\footnotetext{
133 The purpose of copyright is to serve the public interest by providing adequate rewards to authors and encourage the creation of new works and their dissemination to the public. This requires a proper balance between the interests of authors and intermediaries (copyright limitations and exceptions often represent an obstacle to the maximization of profits from the part of intermediaries, although they can sometimes benefit authors) in order to further the general interest of society. See "Declaration on a balanced interpretation of the Three-Step Test in Copyright Law" (with R.M. Hilty, J. Griffiths) in: IIC 2008, 707 ; 2008 EIPR 489.
} 
the "read-only" nature of standard mass media. ${ }^{134}$ On the other hand, users are also turning into active consumers and providers of information: they no longer passively consume information which is unilaterally imparted to them by the mass media, but, rather, carefully select the information that seems the most interesting to them, to subsequently dispatch it to their circles of friends or more broadly share it over the Internet. ${ }^{135}$

These changes may be perceived, from a system theory perspective, as resulting from the evolution of the technological system which led to the subsequent evolution of social norms and practices in the creative and economic systems - and which, in turn, irritated the copyright system. Indeed, given the growing amount of content (both professional and user generated content) that is nowadays freely available online, it becomes more and more difficult for right holders to enforce their exclusive rights over the use of such content. Besides, given the huge amount of information that the public is constantly faced with, consumers' preferences have become a key factor in determining the content that will most likely be consumed.

As such, Internet and digital technologies can be said to have triggered the emergence of new social norms (mostly reflective of a sceptical attitude towards copyright law) that ultimately increased the gap between the subsystem of copyright law and the informal system of norms which emerged within the creative system: the two competing logics responsible for establishing normative expectations as regards the production, dissemination and access to creative works.

A careful reconsideration of the copyright regime has therefore become necessary, with a view of understanding whether - and how - copyright law could eventually adapt to the digital world.

Indeed, the former equilibrium (which was considered to be adequate in the physical world) was constructed on the basis that end-users had no ability through copying to reduce the rewards available to the creators and disseminators of information. Regulation could therefore be designed to preclude commercial/professional actors from infringing the law, without affecting the ability for end-users to act freely in the realm of the private sphere.

Today, however, as end-users have become the main players in the digital realm - capable of both increasing and decreasing the financial rewards for authors and right-holders - it has become crucial that the system evolve to better account for (and benefit from) the new opportunities provided by Internet and the new information and communication technologies. Yet, if one considers the legislative reforms undertaken thus far, it appears that the legal system-did not properly understand ${ }^{136}$ the specificities of digital technologies, or simply refused to adjust to the new environment in which it operates.

In order to restore its original rationale, the copyright regime needs, therefore, to be re-evaluated for it to properly and effectively regulate social dynamics as regards the production, dissemination and access to

\footnotetext{
134 According to Lawrence Lessig, copyright laws changed the dynamics of cultural production by endorsing the concept of a "readonly" culture which the public consumes more or less passively and whose production is reserved to the professionals. Digital technologies contributed to reviving the concept of a "read-write" culture whose production is based on democratic principles and a symmetric (peer-to-peer) approach. See: L. Lessig, Remix: Making art and commerce thrive in the hybrid economy. (Penguin Press 2008).

135 G. Fischer, G. (2002). Beyond 'couch potatoes': From consumers to designers and active contributors. First Monday, 7(12), 137.

136 Referring to the most common objection formulated by the systems' theory opponents to the unnecessary and unfounded personification of the legal system, it is worth underlying that in this model personification serves solely as a metaphor, which simplifies the real life mechanisms for the sake of the clarity of our analysis.
} 
creative works. 
